\title{
Topikal Etofenamat Kullanımına Bağlı Allerjik Kontakt Dermatit Olgusu
}

\section{A Case of Allergic Contact Dermatitis due to Topical Etofenamate}

\author{
Şule Şahin ONAT, Sibel ÜNSAL DELIALIOĞLU*, Demet UÇAR** \\ Ağrı Devlet Hastanesi, Fizik Tedavi ve Rehabilitasyon Kliniği, Ağrı, Türkiye \\ *Ankara Fizik Tedavi ve Rehabilitasyon Eğitim ve Araştırma Hastanesi, Fizik Tedavi ve Rehabilitasyon Kliniği, Ankara, Türkiye \\ **Diyarbakır Eğitim ve Araştırma Hastanesi, Fizik Tedavi ve Rehabilitasyon Kliniği, Diyarbakır, Türkiye
}

\section{Sayın Editör;}

Topikal kullanılan nonsteroid antiinflamatuvar ilaçlarda (NSAil) en sık görülen cilt reaksiyonu allerjik kontakt dermatittir (1). Bunun dışında akut irritan kontakt dermatit, fotoallerjik kontakt dermatit, eksfolyatif dermatit, anjioödem olabilecek diğer yan etkilerdir. Otuz dört yaşındaki bayan hasta servikal disk hernisi nedeniyle etofenamat sprey kullanımından sonra boynun sağ tarafında deri seviyesinde tabanı eritemli, üzerinde yer yer squamların olduğu plak tarzı yaygın makülopapüler lezyon, lezyona eşlik eden şişlik ve kaşıntı şikayetleri ile başvurdu (Resim 1). Hastanın eşlik eden ek bir hastalığı yoktu ve fizik muayenesi ile laboratuvar parametreleri normal olarak değerlendirildi. Yapılan ultrasonografik görüntülemesinde servikal zincirde hilusu ekojen, kısa aks boyutu patolojik olmayan birkaç adet sonografik olarak reaktif görünümlü lenf bezi izlendi. Allerjik kontakt dermatit tanısı düşünüldü ve patch (yama) testiyle allerjenin etofenamat sprey olduğu teyit edildi. Kortikosteroidli krem ve oral antihistaminik ilaç tedavisinden sonra hastanın yoğun kaşıntı, batma, yanma şikayetleri rahatladı, üç gün içerisinde lezyonlar geriledi.

Allerjik kontakt dermatitte (AKD) allerjen madde ile ilk temas sonrası organizmada bu allerjene karşı duyarlılık gelişmesi ve duyarlanmış kişilerde aynı madde ile daha sonraki temaslardan sonra gecikmiş tip (IV) aşırı duyarlılık reaksiyonu söz konusudur (2). Bu hastalarda tanı öykü, dikkatli bir fizik muayene ve yama (patch) testi ile konmaktadır. Yama testi temas eden allerjeni tespit etmek için kullanılan kolay ve güvenli bir provokasyon testidir. Olası allerjen sırt orta hattan 2-4 cm laterale veya üst kolun dış kısmına uygulanıp, bantlanır ve 48. ve 96 . saatte test bölgesi açılır ve bu alanda eritem, papül, vezikül, bül olup olmadığı, boyutları değerlendirilir. Akut irritan kontakt dermatit (AIKD) ise deriye dışardan temas eden bir takım irritan maddelerin deride hücre harabiyeti ve inflamasyon oluşturduğu immünolojik olmayan bir reaksiyondur (2).

Hem AKD hem de AlKD'in her ikisi de epidermiste intertisyel ödeme neden olurken patofizyolojilerinin farklı olması ayırıcı tanıda yardımcı olmaktadır. AKD daha önce allerjen ajan ile karşılaşmış

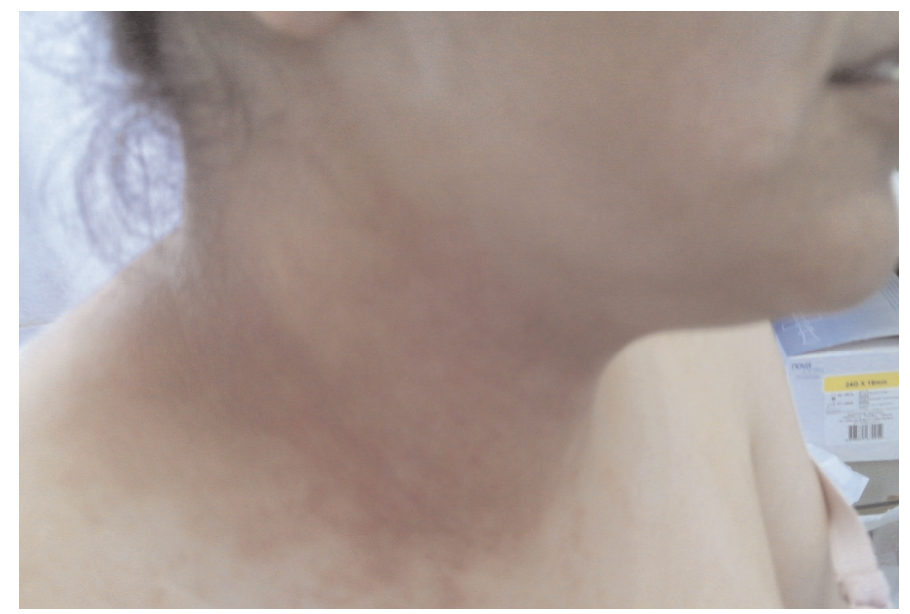

Resim 1. Allerjik kontakt dermatitin boyundaki görüntüsü 
olmayı gerektiren ve allerjen maddenin maruziyet dozuyla tablonun şiddetinin korele olmadığı immünolojik bir reaksiyondur. AiKD ise daha önce etkenle karşılaşma zorunluluğu olmayan, ilk maruziyetten sonra da ortaya çıkabilen, irritan maddenin doğrudan hasarıyla olduğu için maruziyet dozuyla reaksiyonun şiddetinin korele olduğu lokal inflamatuvar bir tablodur (2). Allerjik kontakt dermatitte lezyonlara sıklıkla kaşıntı eşlik ederken AlKD'de kaşıntıdan çok ağrı ve yanma şikayeti ön plandadır. AKD'de maruziyet bölgesinden etraf dokulara yayılım varken AiKD'de lezyon sadece irritan maddenin temas ettiği bölgede sınırlı olmaktadır (2). Olgumuzda etofenamat spreyi hastanın daha önce de kullandığını, fakat herhangi bir yan etkiyle karşılaşmadığını, bu kullanımına fizik tedavi programının eklenmesinden sonra lezyonların ortaya çıktığını ifade etmesi etofenamata bağlı AKD ile AlKD'in ayırıcı tanısını yapmakta güçlük çekmemize neden oldu. Ajanla ikinci karşılaşmadan sonra lezyonların çıkması, sadece spreyin kullanıldığı bölgede değil, etraf dokularda da lezyonların olması, kaşıntının eşlik etmesi allerjik kontakt dermatit tanısını desteklemekteydi. AlKD'de ajanın deriye doğrudan hasarı olmasından dolayı fizik tedavi programından sonra lezyonların başlaması etofenamat spreyin sıcağın etkisiyle lokal kan akımının artması, nem, sürtünme gibi etkilerle doğrudan irritan etkisinin olabileceğini düşündürdü. Çünkü kuru deri kontakt maddeyle daha az reaksiyon verirken aşırı nem, sıcak, soğuk, basınç ve sürtünme maruziyetinde gelişebilecek maserasyondan dolayı deri daha hassas hale gelmektedir. Bu durumda yapmış olduğumuz yama testinin pozitif olması tanımızı AKD olarak kesinleştirdi. Yaptığımız testte hastada üst kolun dış kısmına uyguladığımız etofenamat sprey bölgesinde 48. saatte görülen eritem ve papülleri 2+ olarak değerlendirdik. Eritemin sınırlarının yamanın dışına taşması ve 96. saatteki değerlendirmede de reaksiyonun şiddetinin artması AKD tanımızı desteklemekteydi. Hastanın AíKD olması durumunda eritem ve papüler reaksiyonunun sınırlarının uyguladığımız yama ile sınırlı olmasını ve 96. saatteki okumada reaksiyonun şiddetinin azalmasını beklemekteydik.

Fotoallerjik kontakt dermatit (FAKD) kişinin daha önce karşılaştığı ve duyarlandığı fotoallerjenle sonraki karşılaşmalarında deride ortaya çıkan gecikmiş tip hipersensitivite yanıtıdır. AKD'den farklı olarak bireylerin güneş ışığına maruziyetinin eklenmesiyle ortaya çıkmaktadır. Fotoallerjenin kesin tanısı için photopatch test (fotoyama testi) gerekmektedir (3). Olgumuzun giyim tarzı ve lezyonların oluştuğu boyun bölgesinde güneşe maruziyet olmadığı için, fotoallerjik lezyonların daha çok vezikülobüllözken olgumuzdaki lezyonların makülopapüler ve eritem şeklinde olmasından dolayı topikal etofenamata bağlı FAKD düşünmedik. Gerekli ultraviyole ışığı (5-15 joule/m²) verecek cihazımız olmadığı için fotoyama test yapamamamızı olgudaki klinik eksikliğimiz olarak görüp bu konuya Sánchez-Pérez ve ark. (4)'nın etofenamat jel kullanan hastada AKD ve FAKD'nin birlikteliğini gösterdikleri için dikkat çekmek istedik. Fotoyama testinin donanım yetersizliği nedeniyle yapılamaması önemlidir. Çünkü bu grup hastada fotoyama testi sayesinde tablonun ultraviyole ışığına $\mathrm{mı}$ bağlı olduğu yani AKD veya FAKD, son literatür örneğinde olduğu gibi her ikisinin de mi olduğu ve ayrıca sorumlu ajanın tespiti açısından önemlidir.

Literatürde etofenamata bağlı tanımlanmış irritan kontakt dermatit bulunmazken allerjik ve fotoallerjik kontakt dermatit birçok kez bildirilmiştir $(1,5-8)$. Hatta bir çalışmada etofenamat aril propiyonik asit derivelerinden (deksketoprofen, ketoprofen) sonra ikinci en sık kontakt dermatit ve fotoallerjik kontakt dermatit yapan NSAil olarak gösterilmiştir (8). Etofenamat kullanımına bağlı Correia ve ark. (9) eksfoliatif dermatit, Piñol ve ark. (10) da ürtiker ve anjioödem rapor etmiştir.

Sonuç olarak klinikte çok sık kullandığımız topikal ilaçların yaptığı cilt lezyonları yakından takip edilmelidir. Klinik tablolar benzer olsa da tanılarının farklı olabileceği bilinmelidir. NSAil'ların hem oral hem de topikal kullanımlarında ortaya çıkan cilt yan etkilerinde ilaçların moleküler yapısı önemlidir. Bundan dolayı topikal etofenamatla AKD gelişen hastalarda hem yama testinde hem de tedavide benzer kimyasal yapıda olan diğer topikal ajanların kullanılmaması gerektiği unutulmamalıdır.

\section{Çıkar Çatışması:}

Yazarlar herhangi bir çıkar çatışması bildirmemişlerdir.

\section{Kaynaklar}

1. Goday Buján JJ, Pérez Varela L, Piñeyro Molina F, Díaz Román T, Fonseca E. Allergic and photoallergic contact dermartitis from etofenamate: study of 14 cases. Contact Dermatitis Contact Dermatitis 2009;61:118-20.

2. Przybilla B, Rueff F. Contact Dermatitis. In: Burgdorf WHC, Plewing G, Wolff $\mathrm{HH}$, Landthaler M, editors. Braun-Falco's Dermatology. 3rd ed. Italy. Springer Company. 2009. p. 377-86.

3. Andreu I, Mayorga C, Miranda MA. Generation of reactive intermediates in photoallergic dermatitis. Curr Opin Allergy Clin Immunol 2010;10:303-8.

4. Sánchez-Pérez J, Sánchez TS, García-Díez A. Combined contact and photocontact allergic dermatitis to etofenamate in flogoprofen gel. Am J Contact Dermat 2001;12:215-6.

5. Ophaswongse $\mathrm{S}$, Maibach $\mathrm{H}$. Topical nonsteroidal antiinflammatory drugs: allergic and photoallergic contact dermatitis and phototoxicity. Contact Dermatitis 1993;29:57-64.

6. Hergueta JP, Ortiz FJ, Iglesias L. Allergic contact dermatitis from etofenamate: report of 9 cases. Contact Dermatitis 1994;31:60-2.

7. Götze A, Teikemeier G, Goerz G. Contact dermatitis from etofenamate. Contact Dermatitis 1992;26:209.

8. Goday-Bujan JJ, Rodríguez-Lozano J, Martínez-González MC, Fonseca E. Photoallergic contact dermatitis from dexketoprofen: study of 6 cases. Contact Dermatitis 2006;55:59-61.

9. Correia O, Barros MA. Exfoliative dermatitis with etofenamate. Contact Dermatitis 1984:11:132-3.

10. Piñol J, Carapeto FJ. Contact urticaria to etofenamate. Contact Dermatitis 1984;11:132-3. 